\title{
2016 年我国农产品质量安全网络與情监测与分析
}

\author{
李祥洲 ${ }^{1^{*}}$ ，钱永忠 ${ }^{1 \dagger}$ ，邓玉 ${ }^{1}$ ，宋卫国 ${ }^{2}$, 廖家富 ${ }^{3}$, 杨明升 ${ }^{4}$, 廉亚丽 ${ }^{1}$
}

1. 中国农业科学院农业质量标准与检测技术研究所, 农业部农产品质量安全重点实验室, 北京 100081;

2. 上海市农业科学院农产品质量标准与检测技术研究所, 上海 201106;

3. 重庆市农产品质量安全中心, 重庆 400020;

4. 北京达邦食安科技有限公司, 北京 100083

* 联系人, E-mail: lixiangzhou@caas.cn

$\dagger$ 同等贡献

近年来, 监测分析与应对引导农产品质量安全與情, 及时回应社会关切, 已成为我国农产品质量安全监管的重 要工作之一. 2016 年, 国家农产品质量安全风险评估项目 计划“专业性农产品质量安全與情信息监测及机制构建与 示范” 项目有关研究工作陆续完成, 相继开展了农产品质 量安全网络與情信息监测分析、风险隐患研判及與情报告 编报等工作. 本文通过对全年农产品质量安全與情信息的 实时监测及风险隐患研判, 分析研究了 2016 年我国农产 品质量安全网络與情发生发展的基本规律特征.

\section{1 资料与方法}

2016 年, 农产品质量安全與情监测工作在继承往年 监测分析方法 ${ }^{[1]}$ 的基础上, 更加注重对“互联网+”新技术 的应用, 研发出具自主知识产权的“食安與情监测分析系 统”, 形成了 “平台端+移动端”的全网产品. 與情监测覆盖 传统网络媒体的新闻网站、论坛、贴吧等和新媒体微博、微 信公众账号、微视频及 APP 新闻客户端, 采集网络数据信 息源达 1000 万以上(含主要微博、微信公众账号), 基本实 现了與情信息的全网监控, 避免监测死角. 根据近年来與 情传播发酵的特点 ${ }^{[2,3]}$, 重点加强了对以微博、微信、微视 频和新闻客户端为代表的 “三微一端”渠道的监测力度, 并 通过监测信息平台, 实现对與情传播路径的跟踪溯源.

农产品质量安全网络與情信息监测的对象以食用农产 品为主, 兼顾有可能波及农产品质量安全的食品质量安全 问题. 有关與情初步篮选主要由“食安與情监测分析系统” 自动完成, 與情监测工作人员二次人工篮选, 最终经由专家 学者对热点问题及风险隐患的分析评判和农业部农产品质 量安全监管局组织的应对研判. 基于以上與情数据监测结 果，通过描述性统计和“热搜词”分析等方法，从媒体、时间、 诱因、行业和区域五个角度揭示與情数据的分布特征, 进而 分析提出 2016 年我国农产品质量安全网络與情走势情况.

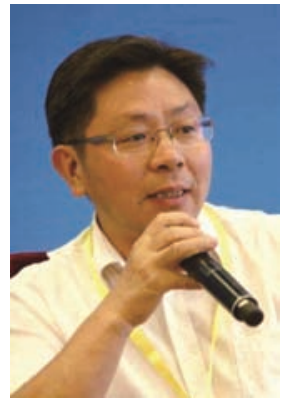

李拜洲中国农业科学院农业质 量标准与检测技术研究所(农业部农 产品质量标准研究中心)政策与信息 研究室主任、学术委员会委员, 三级 研究员, 网络舆情分析师, 兼任《农 产品质量与安全》杂志副主编、全国 无公害农产品认证评审委员会委员 等。主要研究方向是农产品质量安全 信息资源管理。主持了国家农产品质 量安全风险评估项目计划“专业性农产品质量安全與情信 息监测及机制构建与示范”等 20 余项.

\section{2 與情信息数理统计}

2016 年共监测到农产品质量安全相关與情信息 220 万余条，与 2015 年同比下降了 $5.17 \%$. 经过篮选、研判、加 工, 获取值得关注的境内外與情信息(样本)1043 条, 相较 2015 同期基本持平. 在监测到的與情信息(样本)中, 境内 與情信息 927 条，占比 $88.88 \%$; 来自港澳台地区的农产品 质量安全相关與情信息 12 条; 国外农产品质量安全相关 與情信息 104 条, 占比 $9.97 \%$, 涉及世界 20 个主要国家和 地区，监测范围较 2015 年有所扩大.

采用近年来农产品质量安全與情分析的同一统计口 径 ${ }^{[4 \sim 7]}$, 对 2016 年获取的 1043 条與情信息进行分类归并, 结果见表 1.2016 年监测获得的正面與情(包括政策法规措 施类、消费指导类和科技进步类)占比达到 $55.42 \%$ ，连续 4 年超过 50\%, 较 2015 年增加了 0.69 个百分点. 2016 年共监 测到政策法规措施类與情信息 491 条, 占比 $47.08 \%$, 与 2015 年情况基本持平. 2016 年监测到国家或地方出台农产 品质量安全相关“政策法规与制度措施”的與情数量最多, 共计 260 条, 占同类舆情的 $52.95 \%$, 较 2015 年增加了 5.48 个百分点, 增幅显著; 体现监管部门就农产品质量安全开 展督查整治及其结果成效的“督查整治及结果成效类”與情 


\section{表 12016 年境内外农产品质量安全网络舆情信息统计}

Table 1 Statistics on agro-products quality and safety public opinion in 2016

\begin{tabular}{|c|c|c|c|c|}
\hline & 舆情分类 & 與情样本数(个) & 合计(个) & 所占比例 $(\%)$ \\
\hline \multirow[t]{5}{*}{ 政策法规措施类 } & 政策法规与制度措施 & 260 & \multirow[t]{5}{*}{491} & \multirow[t]{5}{*}{47.08} \\
\hline & 督查整治及结果成效 & 110 & & \\
\hline & 重要活动讲话指示 & 58 & & \\
\hline & 问题事件处置回应 & 35 & & \\
\hline & 标准制修订 & 28 & & \\
\hline \multirow{8}{*}{ 质量安全问题事件类 } & 违禁农兽渔药及农兽渔药残留 & 87 & \multirow[t]{8}{*}{234} & \multirow[t]{8}{*}{22.44} \\
\hline & 制假售假及违法违规加工 & 33 & & \\
\hline & 非法添加 ～～～～～～～～ & 30 & & \\
\hline & 致病微生物及寄生虫污染 & 28 & & \\
\hline & 重金属超标及产地环境污染 & 19 & & \\
\hline & 动植物疫病 & 17 & & \\
\hline & 自身毒素及代谢产物 & 12 & & \\
\hline & 商标标注不合格 & 8 & & \\
\hline 恶意攻讦类 & 传言谣言 & 120 & 120 & 11.51 \\
\hline 消费指导类 & 消费指导及科学普及 & 58 & 58 & 5.56 \\
\hline 科技进步类 & 科学研究发明发现 & 29 & 29 & 2.78 \\
\hline \multirow{2}{*}{ 科学缺陷类 } & 科学争议问题 & 10 & \multirow{2}{*}{24} & \multirow{2}{*}{2.30} \\
\hline & 标准差异及标准缺失 & 14 & & \\
\hline \multirow{3}{*}{ 其他 } & 建言建议 & 37 & \multirow{3}{*}{87} & \multirow{3}{*}{8.33} \\
\hline & 社会调查 & 38 & & \\
\hline & 人物访谈 & 12 & & \\
\hline 总计 & & 1043 & & 100 \\
\hline
\end{tabular}

占比 $22.40 \%$; “重要活动讲话指示类”、“问题事件处置回应 类” 和 “标准制修订类” 與情分别占比 $11.81 \%, 7.13 \%$ 和 $5.70 \%$ ，与 2015 年情况基本持平.

负面舆情(包括质量安全问题事件类)占比 $22.44 \%$, 占 比数连续 3 年下降, 较 2015 年下降了 4.69 个百分点. 其中, “违禁农兽渔药残留超标”和“制假售假及违法违规加工”类 與情自 2013 年以来一直是负面舆情的最主要构成. 2016 年, 这两类舆情在负面舆情中分别占比 $37.18 \%$ 和 $14.10 \%$, 总 占比 $51.28 \%$, 首次超过 50\%. 此外, “非法添加” (12.82\%)、 “致病微生物及寄生虫污染” (11.97\%) 和 “动植物疫病” (7.26\%)也是负面舆情的重要构成.

中性與情(包括科学缺陷类、其他等)数量占比 $22.14 \%$, 较 2015 年同期增加了 4 个百分点, 占比数连续 2 年增长. 2016 年传言谣言类舆情信息数量增幅明显, 较 2015 年增 长了 $51.90 \%$. 有关农产品及食品质量安全问题的科普宣 传、辟谣类舆情信息较 2015 年显著增多, 占比 $5.56 \%$, 较 2015 年增加了 2.16 个百分点. 特别是针对近年来反复多次 炒作问题的科普解读, 受到网民的普遍欢迎.

利用开源分词工具, 将 2016 年获取并编发的 1043 条
境内外與情信息(样本)标题输人系统, 自动分词并统计词 频, 去除无实际意义的词, 统计结果见表 2. 从表 2 看出, 2016 年涉及农产品质量安全的媒体报道中, “农产品质量 安全”作为关键词出现频次最高, 共出现 138 次. “农药”和 “兽药”分别出现了 90 次和 24 次, “残留超标”出现了 58 次, 这反映出公众对农产品农兽药残留超标问题的高度关注. “抗生素”作为一个独立关键词出现了 27 次. “辟谣”(67 次) 和“谣言”(21 次)两个关键词多次出现, 反映出公众对农产 品营养功能关注度的持续提升, 以及对食用农产品质量安 全相关谣言及其科普宣传的关切. 《人民日报》多次刊文 关注农产品质量安全相关问题. 2016 年 9 月 13 日, 《人民 日报》求证栏目刊文《“无籽葡萄抹避孕药”纯属无稽之谈》, 就“无籽葡萄抹避孕药”等问题进行了专题科普. 2016 年 1 月, 国务院办公厅印发《关于加快推进重要产品追溯体系 建设的意见》, 2016 年 6 月, 农业部印发《关于加快推进 农产品质量安全追溯体系建设的意见》, 多地农产品质量 安全追溯体系建设进人快车道, “追溯”(26 次)成为 2016 年 的一个重要关键词.

单独对“质量安全问题事件类”舆情样本进行分析, 结 
表 22016 年农产品质量安全舆情信息关键词词频统计(Top 30)

Table 2 Agro-products quality and safety public opinion information keywords frequency statistics in 2016 (Top 30)

\begin{tabular}{clc||clc}
\hline 序号 & \multicolumn{1}{|c||}{ 关键词 } & 词频 & 序号 & 关键词 & 词频 \\
\hline 1 & 农产品质量安全 & 138 & 16 & 广东 & 21 \\
2 & 农业部 & 91 & 17 & 猪肉 & 20 \\
3 & 农药 & 90 & 18 & 畜禽 & 20 \\
4 & 辟谣 & 67 & 19 & 致癌 & 19 \\
5 & 食品安全 & 63 & 20 & 屠宰 & 17 \\
6 & 残留超标 & 58 & 21 & 蔬菜 & 16 \\
7 & 抗生素 & 27 & 22 & 标准 & 16 \\
8 & 水产品 & 27 & 23 & 湖南 & 15 \\
9 & 追溯 & 26 & 24 & 茶叶 & 15 \\
10 & 进出口 & 25 & 25 & 水果 & 15 \\
11 & 兽药 & 24 & 26 & 瘦肉精 & 15 \\
12 & 人民日报 & 23 & 27 & 专项整治 & 15 \\
13 & 美国 & 22 & 28 & 蔬菜 & 15 \\
14 & 谣言 & 21 & 29 & 茶叶 & 15 \\
15 & 有机农产品 & 21 & 30 & 激素 & 14 \\
\hline
\end{tabular}

果见表 3. 从表 3 可以看出, 2016 年农产品质量安全负面與 情涉及较多的高敏农产品包括有机农产品、蜂蜜、牛肉、蔬 菜、水产品、猪肉、鸡蛋、茶叶、草莓和豆芽等; 高敏危 害因子有农兽药残留超标、动物疫病、避孕药、沙门氏菌 感染、违规使用抗生素、瘦肉精、孔雀石绿等. 2016 年, 涉 及产品质量安全的关键词“避孕药”出现了 11 次. 分析发现, 與情中所涉及的“避孕药”多是由于消费者乃至部分媒体从 业人员缺乏生物学常识所致, 特别是一些网民混淆了植物 性激素与动物性激素区别, 产生诸如无籽瓜果、黄瓜顶花 带刺是抹了避孕药的误解.

\section{3 网络與情特征分析}

\section{1 诱因特征}

2016 年共监测获取农产品质量安全相关與情信息 1043 条, 如扣除同一问题事件的跟踪與情, 实际监测获得 與情信息 976 条(个), 其中农产品质量安全问题事件相关 與情信息 227 条(个). 以此为对象, 分析农产品质量安全问 题事件网络與情形成的原因. 结果显示, 2016 年, “农业投 人品”问题是引发网络與情的首要原因, 占比 $37.44 \%$, 全 年相关與情共 85 条, 较 2015 年增长了约 $10 \%$. 排名第二 的是 “制假售假及违法违规加工”, 全年相关與情共 31 条, 占比 $13.66 \%$. 农产品进入流通或销售环节等环节后出现的 违法违规加工问题近年来一直处在高发态势 ${ }^{[4,5]}$. “非法添
表 32016 年农产品质量安全负面舆情信息关键词词频统计 (Top 20)

Table 3 Agro-products quality and safety negative public opinion information keywords frequency statistics in 2016 (Top 20)

\begin{tabular}{clc||clc}
\hline 序号 & 关键词 & 词频 & 序号 & 关键词 & 词频 \\
\hline 1 & 残留超标 & 63 & 11 & 瘦肉精 & 8 \\
2 & 农药 & 21 & 12 & 蔬菜 & 7 \\
3 & 动物疫病 & 20 & 13 & 孔雀石绿 & 7 \\
4 & 有机农产品 & 12 & 14 & 水产品 & 7 \\
5 & 避孕药 & 11 & 15 & 猪肉 & 6 \\
6 & 沙门氏菌 & 9 & 16 & 鸡蛋 & 5 \\
7 & 蜂蜜 & 9 & 17 & 䒩叶 & 4 \\
8 & 牛肉 & 8 & 18 & 草莓 & 4 \\
9 & 兽药 & 8 & 19 & 豆芽 & 4 \\
10 & 抗生素 & 8 & 20 & 大米 & 3 \\
\hline
\end{tabular}

加”诱因在 2016 年呈抬头趋势，占比分别达到 $13.22 \%$, 排 名较前一年上升 1 位. 2016 年，媒体和网民对“自身毒素及 代谢产物”诱发的相关與情关注度出现了显著回落现象, 同类占比 $5.29 \%$, 下降了 2.71 个百分点. 其他引发农产品 质量安全问题事件网络與情的成因还有致病微生物及寄 生虫污染、产地环境污染、动植物疫病和产品标识混乱等, 情况与往年基本持平.

\section{2 行业特征}

参考农业部农产品质量安全例行监测统计的口径, 对 农产品质量安全问题事件與情涉及的行业进行了适当的 统计归并. 数据显示, 种植业和畜牧业是农产品质量安全 问题事件與情多发的行业，综合占比 $63.43 \%$. 其中种植业 相关與情数量占比 $35.24 \%$, 较前一年下降了 4.4 个百分点, 降幅显著. 2016 年, 因水产品质量安全问题引发的网络與 情数量连续 2 年增加, 占比 $18.06 \%$, 较 2015 年同期上升 3.51 个百分点. 从各行业分别来看, 种植业中主要存在禁 限用农药的违规使用 $(46.25 \%)$ 、非法添加非食用物质 (16.25\%)和微生物毒素污染 $(13.75 \%)$ 等问题; 畜牧业中主 要存在违禁兽药及抗生素残留超标 $(46.88 \%)$ 、疫病动物流 人市场 $(21.88 \%)$ 和屠宰加工不规范 $(20.31 \%)$ 等问题; 渔业 中主要存在违禁鱼药残留 (36.59\%)和违规使用孔雀石绿 (26.83\%)和养殖环境污染 (19.51\%)等问题. 2016 年 11 月, 香港食安中心报告称检出大陆产大闸蟹二噁英超过行动 水平, 疑似因养殖环境污染所致.

从农田到餐桌的环节来看, 生产环节和初加工环节仍 是农产品质量安全最容易发生问题事件與情的环节，分别 占比 $57.27 \%$ 和 $19.38 \%$. 生产环节所涉與情数量占比已连 续两年超过 $50 \%$, 较前一年同期增加了 6.36 个百分点. 2016 年, 储运保鲜环节相关與情占比 $14.10 \%$, 连续 2 年呈 
上升趋势. 2016 年, 鲜活水产品在储运保鲜过程中违规使 用孔雀石绿等问题受到媒体和网民的广泛关注, 孔雀石绿 “久禁不绝”被多家媒体提及并引发與情热点. 销售环节曝 光问题事件舆情数量则有下降趋势, 2016 占比 $9.25 \%$, 较 前一年下降了 2.39 个百分点.

\section{3 媒体特征}

2016 年监测到的相关网络與情样本共来自国内外的 330 种媒体信息源, 较 2015 年增加了 87 种. 其中境内信息 源 286 种(不包括港澳台), 占比 $86.67 \%$, 共监测舆情样本 987 个; 境外信息源 44 种, 占比 $13.33 \%$, 共监测舆情样本 56 个.

从媒体的类型分布来看, 2016 年网络媒体依然是获取 與情信息的最主要来源, 总占比 $55.32 \%$, 连续 3 年超过 $50 \%$. 其中, 来自网站的舆情信息 537 条, 占比 $51.49 \%$. 近 年来, 以微信、微博、微视频和新闻客户端为代表的“三微 一端”类媒体贡献抢眼 ${ }^{[8]}$. 2016 年, $3.83 \%$ 的與情信息首发 来自于 “三微一端”, 且以负面或谣言性與情为主. 2016 年 “微视频”中第一次监测到农产品质量安全舆情信息, 成为 农产品质量安全舆情信息源. 例如 2016 年网络中热传的 “避孕药葡萄”、“蘸药蒜臺” 和“催熟香蕉”等谣言都是以微 视频的形式出现并传播. 谣言视频往往通过模糊关键信息 (时间、地点、使用剂量等)的手法, 将原本明显缺乏常识的 谣言包装成看似有理有据的 “新闻发现”, 赚取点击量. 数 据显示, “三微一端”已经成为网络中反复炒作的农产品质 量安全各类传闻、传言和谣言的发酵温床, 特别是微信朋 友圈在农产品质量安全问题事件中的舆情传播功能正在 急速放大. 2016 年传统媒体第一时间报道(曝光)有关农产 品质量安全信息总占比 $44.68 \%$. 传统媒体来源中, 报纸依 然是與情监测的最重要渠道, 获取信息数量占比 $40.94 \%$; 以中央电视台为代表的广播、电视渠道占比 $3.16 \%$, 期刊 仅占 $0.58 \%$.

进一步梳理出境内信息来源的前 15 位和境外信息来 源的前 5 位, 可以看出, 境内第一时间报道(曝光)涉及农产 品质量安全的仍以传统媒体为主, 主要包括新华网/新华 社(141)、农业部网/中国农业信息网(92)、人民日报/人民网 (66)、农民日报/中国农业新闻网(45)、经济日报/中国经济 网(40)、中国新闻网/中新社(27)、新京报(25)、中央电视台 (19)、广州日报(14)、北京青年报(12)、央广网(12)、齐鲁 网(10)、法制晚报(9)、齐鲁晚报(9)和南方日报(8)等(括号 中数字为 2016 年该媒体首发舆情信息数量, 下同). 境外 涉及农产品质量安全與情信息源前 5 包括美国食品安全新 闻网(4)、英国金融时报网(4)、韩国 thinkfood 网(2)、韩国 食品新闻网(2)及美国疾病预防控制中心网(2)等, 主要集 中于美国、韩国、英国等发达国家和地区. 2016 年境内前 15 和境外前 5 种信息来源获取的舆情信息占與情信息样本
总量的 $52.06 \%$. 由此可见, 国家级媒体和行业或区域性大 型传统媒体依然是报道、曝光或引发农产品质量安全网络 舆情的主流媒体.

分析不同媒体来源與情信息的调性情况, 结果显示, 2016 年关注和报道农产品质量安全正面與情信息的媒体 有 166 种, 占比 $52.70 \%$, 首发正面與情信息数量排前 10 的包括农业部网/中国农业信息网(78)、新华网/新华社(73)、 人民日报/人民网(40)、农民日报/中国农业新闻网(35)、经 济日报/中国经济网(22)、中国新闻网/中新社(15)、国家食 品药品监督管理总局网(6)、新京报(6)、中国政府网(6)和 黑龙江日报(5)等．以上媒体配合农业主管部门，开展了大 量农产品质量安全政策制度宣传、监管整治成果展示以及 食用农产品质量安全科普解读及风险交流工作. 2016 年第 一时间关注和报道农产品质量安全负面舆情信息的媒体 有 171 种, 占比 $54.29 \%$, 首发负面與情信息数量排前 10 的包括新华网/新华社(32)、微信公众号(23)、新京报(11)、 广州日报(6)、齐鲁网(6)、中国质量新闻网(6)、中央电视 台(6)、人民网(5)、食品伙伴网(5)和中国新闻网/中新社 (5)等.

\section{4 时间特征}

2016 年各月份监测获得的有效與情数量和相应的质 量安全问题事件类與情信息数量变化情况见图 1. 从总体 上看, 2016 年有效與情数量和相应的质量安全问题事件與 情数量波动态势大体一致, 但二者峰值出现的时间则不相 同. 2016 年农产品质量安全有效與情的峰值出现在 3 月, 而质量安全问题事件相关與情的峰值出现在 8 月. 在波动 趋势上，1 2 月仍然是舆情比较少的时段，2 月中下旬之后 逐步上扬, 到 4 月份达到春季问题舆情的一个高点, 之后 有一段时间的下探. 6 7 月, 夏季與情进人上升通道, 8 月 初问题事件舆情大幅上扬，创出年内问题事件舆情高点. 8 月下旬以后, 與情开始整体回落, 并在 10 月初恢复到年初 的水平. 与往年不同的是, 2016 年出现了一波明显的问题 事件秋冬與情, 10 月中下旬舆情总体走势出现明显上扬并 在 12 月创出年内高点, 由质量安全问题事件所引发的舆 情占比也出现了上扬.

在图 1 中还可以看到, 各月份中质量安全问题事件與 情占总数的比例, 其中 1 月、 4 月、 5 月、 8 月、 11 月和 12 月这 6 个月中, 质量安全问题事件與情数占比超过平均 水平. 尤其是 2016 年 8 月份, 质量安全问题事件舆情数占 比达 $34.09 \%$, 成为年内问题事件與情数量最多的月份.

近年来，围绕食用农产品质量安全问题的各类传闻、 传言和谣言在网络中层出不穷. 分析显示, 2016 年 3 7 月 和 9 11月是传言、谣言类與情的活跃期，舆情数量出现“井 喷式”增长, 该类與情数量的峰值出现在 5 月和 11 月. 传言、 谣言类舆情活跃期与相关农产品集中上市时节基本一致. 

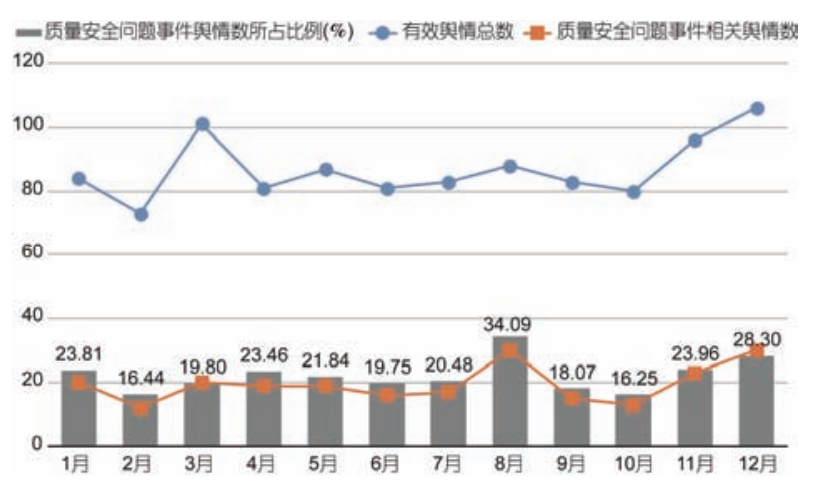

图 12016 年度农产品质量安全有效舆情及问题事件舆情逐月变 化情况

Figure 12016 annual agro-products quality and safety public opinion changes

\section{5 区域特征}

对與情样本中涉及的地区按始发省(市、区)归并后发 现, 除涉及全国性和模糊性区域與情之外, 有明确地区指 向的共涉全国 30 个省、自治区、直辖市. 2016 年境内农产 品质量安全與情总数及问题事件與情信息区域分布情况 见表 4. 从表 4 可以看出, 山东、广东、湖南、北京和黑龙 江等省市的媒体和网民更多关注农产品质量安全状况. 就 负面與情而言, 广东、山东、福建、湖南和江苏 5 省是相 关與情聚焦的重点地区, 合计占比 $28.63 \%$. 其他诸如北 京、重庆、浙江、海南、河北、陕西、河南、上海也是相 关與情的关注热点地区. 综合来看, 我国农产品质量安全 舆情被关注的重点地区依然主要分布在农业主产区省份 和消费大省(市).

2016 年, 监测获得香港特别行政区农产品质量安全 與情信息 9 条, 其中问题事件 4 条; 中国台湾 2 条, 其中问 题事件 1 条. 监测编报国外有关农产品质量安全的與情信 息 104 条, 其中质量安全问题事件 44 条.

\section{4 网络與情走势}

\section{1 农产品质量安全科学监管进入新阶段, 网络 舆情走势总体平稳向好}

2016 年 3 月, 我国发布《国民经济和社会发展第十三 个五年规划纲要》, 要求确保农产品质量安全, 促进农业 可持续发展, 实施食品安全战略. 围绕“十三五规划纲要” 提出的要求, 各级农业部门相继在“农业现代化规划”、“生 猪行业发展”、“农产品追溯体系建设”和“抗生素、禁用化 合物及农兽药残留超标整治”等方面集中部署、密集发力、 强化执行, 多举措保障“十三五”期间我国农产品质量安全. 10 月, 中共中央、国务院印发了《“健康中国 2030”规划纲 要》, 从居民健康角度提出要加强食品安全监管, 完善食
表 42016 年境内农产品质量安全舆情总数及问题事件舆情信 息区域分布

Table 4 The total number of public opinion and negative public opinion in each province

\begin{tabular}{lcc||ccc}
\hline 地区 & $\begin{array}{c}\text { 舆情总数 } \\
\text { (个) 问题事件 } \\
\text { 数(个) }\end{array}$ & 地区 & $\begin{array}{c}\text { 舆情总数 } \\
\text { (个) 问题事件 }\end{array}$ & 数(个) \\
\hline 山东 & 43 & 20 & 四川 & 10 & 2 \\
广东 & 38 & 21 & 河南 & 9 & 4 \\
湖南 & 22 & 8 & 江西 & 9 & 3 \\
北京 & 20 & 6 & 广西 & 8 & 3 \\
黑龙江 & 18 & 2 & 湖北 & 8 & 3 \\
天津 & 18 & 2 & 甘肃 & 7 & 3 \\
浙江 & 18 & 5 & 吉林 & 5 & 1 \\
海南 & 15 & 5 & 内蒙古 & 5 & 1 \\
河北 & 14 & 5 & 上海 & 5 & 4 \\
陕西 & 13 & 4 & 云南 & 5 & 3 \\
安徽 & 12 & 3 & 宁夏 & 4 & 1 \\
福建 & 12 & 9 & 山西 & 4 & 2 \\
江苏 & 12 & 8 & 新疆 & 4 & 1 \\
重庆 & 11 & 6 & 青海 & 2 & 0 \\
辽宁 & 10 & 2 & 贵州 & 1 & 1 \\
\hline
\end{tabular}

品安全标准体系. 12 月, 中央农村工作会议要求把提高农 产品质量放在更加突出位置, 促进农业农村发展由过度依 赖资源消耗、主要满足“量”的需求, 向追求绿色生态可持 续、更加注重满足“质”的需求转变. 农业部门积极与食药 监等部门展开合作, 联合开展农兽药残留问题执法. 6 月, 农业部等 8 部门联合印发《“互联网+”现代农业三年行动实 施方案》指出, 建设质量安全追溯平台, 形成全国一盘棋 的农产品质量安全追溯体系. 7 月, 农业部印发通知, 加快 建立产地准出管理与市场准人管理衔接机制, 开展食用农 产品合格证管理试点. 各级农业部门不断推进依法监管、 科学监管, 有效保障了“舌尖上的安全”. 2016 年全网负面 與情数量明显下降, 问题程度明显减弱, 影响面明显收窄 向好. 全年没有发生重大农产品质量安全网络與情事件.

\section{2 农产品质量安全科普解读不断深化, 公众对 农产品营养功能关注度持续提升}

2016 年, 农产品质量安全谣言问题继续受到全社会 的广泛关注, 有关农产品及食品质量安全问题的科普宣 传、辟谣类與情信息稳步增加，以农业部为主导的我国农 产品质量安全科普解读正不断走向深人和例行常态化. 对 潜在谣言风险进行预判与评估, 在特殊时点针对特定品种 开展主动科普, 针对网络中出现的农产品质量安全谣言, 相关辟谣和科普解读信息密集有目标性的发布, 较以往更 为及时有效. 2016 年, 农业部组织各农产品质量安全风险 
评估实验室和农产品质量安全专家依托《人民日报》和《农 民日报》, 多频次地专刊推出了关于我国奶产品、茶叶产 品、果品、水产品、植物生长调节剂等农产品质量安全水 平提升和科普解读宣传系列文章, 被新华网、中新网、搜 狐网等主流网络媒体大量转载传播, 对提升公众对我国农 产品消费信心发挥了重要的引导作用. 针对媒体近年来反 复炒作的“蒜䔔保鲜”、“空心草莓”、“蘑菇重金属”、”无籽 葡萄”、“牛奶致癌”和“红心甘蔗”等网络谣言, 农业部组织 农产品质量安全风险评估专家利用新华网、中国食品辟谣 联盟、农产品质量安全科普天地微信公众号等主流媒体和 自媒体发表各类针对性的科普辟谣文章 192 篇, 及时回应 了公众关切、消除了消费者的误解和疑虑. 另外, 农业部 在农产品质量安全科普宣传形式上也有了深化创新, 创设 了微访谈、微视频等互动性强、真实生动的连环画式的卡 通形象宣传方式, 受到消费者欢迎. 农业部农产品质量安 全专家编导的“空心草莓”、“避孕药黄瓜”、“甲醛白菜”等 正面的科普视频在微信、微博中大量转载传播, 科普宣传 收到了很好的效果.

2016 年, 我国加大了网络與论环境的监管力度, 加强 了对网络空间的法制监管, 加速推动了网络命运共同体的 构建 ${ }^{[8]} .2016$ 年 7 月国务院办公厅下发了《关于在政务公 开工作中进一步做好政务與情回应的通知》, 部署了进一 步做好政务與情回应工作. 据监测, 随着公众质量安全意 识和健康意识的不断提升, 对农产品的营养功能和产地环 境污染等方面的关注度也在持续提高. 由于公众及媒体人 对农产品生物学特性、营养功能、生长环境特点等方面知 识缺乏 ${ }^{[9,10]}$, 由此引发的社会谣言、传言和误解众多, 今后 农产品生物学特性、营养功能和生长环境方面的应对引导 工作应予以高度重视和不断强化.

\section{3 禁限用农兽药的违规使用仍然是媒体及公众 关注的焦点, 养殖产品抗生素滥用问题與情 走高}

数据显示, 禁限用农兽药的违规使用问题一直是媒体 和公众关注的重点, 且由其引发的相关质量安全问题事件 與情有逐年上升的趋势. 2016 年是全面实行新《食品安全 法》的一年. 新法对禁限用农兽药的违规使用问题有更为严 厉的要求, 相关與情也成为媒体及公众关注重点. 禁限用农 兽药违规使用问题再次成为引发农产品质量安全网络舆情 问题的首要因素. 2016 年 2 月, 媒体援引某些学者初步研究
成果, 声称江浙沪儿童体内普遍有兽用抗生素, 可致儿童肥 胖; 2016 年两会期间, 多位代表建言“禁止在饲料中添加抗 生素”; 2016 年 9 月在杭州召开的二十国集团领导人杭州峰 会集中关注抗生素耐药性问题, 各国领导人呼吁采取包容 的方式应对抗生素耐药性问题, 国内外媒体对畜禽产品抗 生素滥用问题的关注度不断增加, 引起公众持续热议.

\section{4 畜禽产品及水产品與情被关注度逐渐走高, 农产品质量安全源头治理仍需加强}

数据显示, 2016 种植业产品依然是农产品质量安全负 面與情聚集度较高的产品种类, 畜禽产品及水产品與情的 被关注度有快速推高的趋势, 水产品质量安全问题引发的 网络與情数量连续 2 年成为热点. 药物违规使用和非法添 加是诱发畜禽产品和水产品质量安全问题的最主要原因. 处于产业链前端的生产和产地初加工环节是农产品质量 安全最容易出问题的环节, 同时也是最容易引发相关网络 與情热点的环节, 农产品质量安全源头治理量大面广, 任 务艰巨，责任重大，公众期待强烈.

\section{5 “三微一端”进一步主导社会與论议程, 传统 权威媒体及其融媒体产物是开展农产品质量 安全风险交流的主要阵地}

随着网络人群的不断扩大和公众阅读习惯的逐渐改 变, 社会與论的议程设置更多地来自于互联网, 以微博、 微信、微视频和新闻手机客户端为代表的“三微一端”对社 会與论议程设置的主导作用日益凸显, 传统媒体的议程设 置能力有所减弱 ${ }^{[11]}$. 监测数据显示, “三微一端”传递的农 产品质量安全與情信息数量已超过广播电视, 成为农产品 质量安全问题與情传播、发酵的主要场所.

近年来，在媒体融合大趋势的影响下，各种信息媒介 呈现多功能一体化的趋势, 與情信息渠道的边界逐渐趋于 模糊 ${ }^{[12]}$. 以@人民日报、@央视新闻、@新华社发布、@ 澎看新闻、@凤凰资讯等为代表的众多传统媒体进军新媒 体, 把报纸、电视台、电台等传统媒体, 与互联网、手机、 手持智能终端等新兴媒体传播通道有效结合起来, 打通了 体制内外“两个與论场”, 开始影响网络與论场的议程设置. 监测数据显示，人民日报、中央电视台、新华网、农民日 报等传统权威媒体及其融媒体产物已成为农产品质量安 全科普传播与正面风险交流的最主要阵地. 


\section{参考文献}

1 Li X Z. An Introduction to the Monitoring and Analysis of Public of Agricultural Products Quality and Safety (in Chinese). Beijing: China Agricultural Press, 2015 [李祥洲. 农产品质量安全與情监测分析概论. 北京：中国农业出版社, 2015]

2 Hong W, Wu L H. China Food Safety Network Public Opinion Development Report, 2015 (in Chinese). Beijing: China Social Science Press, 2015 [洪巍, 吴林海. 中国食品安全网络舆情发展报告, 2015. 中国社会科学出版社, 2015]

3 Hong W, Wu L H. China Food Safety Network Public Opinion Development Report, 2016. China Social Science Press, 2016 [洪巍, 吴 林海. 中国食品安全网络舆情发展报告, 2016. 中国社会科学出版社, 2016]

4 Li X Z, Qian Y Z, Deng Y, et al. Analysis and prediction of public opinion on agricultural product quality safety network, 2015-2016 (in Chinese). Qual Saf Agro-Prod, 2015, (1): 41-47 [李祥洲, 钱永忠, 邓玉, 等. 2015 2016 年我国农产品质量安全网络與情分析及预测. 农产品质量与安全, 2016, (1): 8-14]

5 Li X Z, Qian Y Z, Deng Y, et al. Research on the development trend of China's internet public opinion towards agro-products quality and safety in 2014 (in Chinese). Qual Saf Agro-Prod, 2015, (1): 41-47 [李祥洲, 钱永忠, 邓玉, 等. 2014 年农产品质量安全网络與情特征 分析研究. 农产品质量与安全, 2015, (1): 41-47]

6 Li X Z, Qian Y Z, Lian Y L, et al. Analysis on the development trend of China's internet public opinion towards agro-products quality and safety in 2013 (in Chinese). Qual Saf Agro-Prod, 2014, (1): 56-61 [李祥洲, 钱永忠, 廉亚丽, 等. 2013 年农产品质量安全网络與 情发展趋势监测与分析. 农产品质量与安全, 2014, (1): 56-61]

7 Li X Z, Qian Y Z, Lian Y L, et al. Monitoring and analysis on the tendency of online public opinion toward agro-product quality and safety (in Chinese). Qual Saf Agro-Prod, 2013, (1): 47-51 [李祥洲, 钱永忠, 廉亚丽, 等. 农产品质量安全网络與情走势监测与分析. 农产品质量与安全, 2013, (1): 47-51]

$8 \mathrm{Lu} \mathrm{W}$. Persisting in respecting the principle of network sovereignty and promoting the construction of network space destiny communitylearning and thinking of the important speech spirit of general secretary Xi Jinping at the second world internet conference (in Chinese). Chin Inf Secur, 2016, (3): 18-21 [鲁炜. 坚持尊重网络主权原则推动构建网络空间命运共同体一一学习习近平总书记在第二届世界 互联网大会上重要讲话精神的体会与思考. 中国信息安全, 2016, (3): 18-21]

9 Zhang J Y, Chen J, Deng Z X. Investigation on consumers' cognition and public participation in quality and safety of agro-products (in Chinese). World Survey Res, 2013, (5): 17-20 [张静宜, 陈洁, 邓志喜. 农产品质量安全消费者认知与公众参与情况调查. 调研世界, 2013, (5): 17-20]

10 Chen S, Xu J, Xiao M, et al. Beijing public risk perception of food safety from the perspective of risk communication (in Chinese). J Chin Inst Food Sci Technol, 2014, 14: 176-181 [陈思, 许静, 肖明, 等. 北京市公众食品安全风险认知调查一从风险交流的角度. 中国食品学报, 2014, 14: 176-181]

11 Li L P. Social Blue Book-Analysis and Forecast of Chinese Social Situation in 2016 (in Chinese). Beijing: Social Science Literature Publishing House, 2015 [李培林等. 社会蓝皮书—2016 年中国社会形势分析与预测. 北京: 社会科学文献出版社, 2015]

12 Gao X H. Getting out of the predicament: Opinion guide of traditional media in the context of media convergence (in Chinese). Soc Sci, 2015, (9): 154-160 [高晓虹. 媒体融合新常态下传统媒体舆论引导面临的困境与出路. 社会科学, 2015, (9): 154-160] 


\title{
Monitoring and analysis on internet public opinion of agro-products quality and safety in China, 2016
}

\author{
LI XiangZhou $^{1 *}$, QIAN YongZhong ${ }^{1 \dagger}$, DENG Yu $^{1}$, SONG WeiGuo ${ }^{2}$, LIAO JiaFu $^{3}$, \\ YANG MingSheng ${ }^{4} \&$ LIAN YaLi ${ }^{1}$ \\ ${ }^{1}$ Institute of Quality Standards \& Testing Technology for Agro-products, Chinese Academy of Agricultural Sciences, Key Laboratory for Agro-product \\ Quality and Safety, Ministry of Agriculture, Beijing 100081, China; \\ ${ }^{2}$ Institute of Quality Standards \& Testing Technology for Agro-products, Shanghai Academy of Agricultural Sciences, Shanghai 201106, China; \\ ${ }^{3}$ Chongqing Agro-products Quality and Safety Center, Chongqing 400020, China: \\ ${ }^{4}$ Beijing Dabang Food Safety Technology Co. Ltd., Beijing 100083, China \\ * Corresponding author, E-mail: lixiangzhou@caas.cn \\ $\dagger$ Equally contributed to this work
}

Based on both real-time tracking monitoring and comprehensive evaluation on agro-products quality and safety public opinion information by intelligent platform and manpower, the public opinion information in 2016, could be divided into 7 categories and 21 sub-categories, in which positive accounting for more than 50\%, however negative showed a downward trend for three years. Overall, in 2016, there was no major event about agro-products quality and safety internet public opinion. The number of negative public opinion steadily declined, and relevant internet public opinion steady trend for better. The results of monitoring and analysis showed that, organic agro-products, honey, beef, vegetables, aquatic products, pork, eggs, tea, strawberries and bean sprouts are high-sensitivity agro-products for public opinion; agricultural and veterinary drug residues exceeded, animal diseases, contraceptives, Salmonella infection, illegal use of antibiotics, clenbuterol, malachite green are the annual high-risk factor. Agricultural inputs problem came to be the primary cause of negative internet public opinion, accounting for $37.44 \%$; illegal add incentives rebounded in 2016; media and netizens' attention on public opinion caused by toxins and metabolites dropped significantly. Farming and animal husbandry are agro-products quality and safety negative public opinion problem-prone industry, accounting for $63.43 \%$ overall; public opinion attention on livestock \& poultry products and aquatic products gradually increased. Agro-products quality and safety negative public opinion often appear in production link and primary processing link, accounting for $57.27 \%$ and $19.38 \%$; problems like adding illegally malachite green during storage and transportation are widespread concerned by the media and netizens. Data shows that, The sources of these agro-products quality and safety public opinion information come to 330 domestic and foreign media, in which the most important source is online media; public opinion contribution rate of micro-blog, WeChat, micro-video and APP have exceeded the radio and television, and been becoming the main place for public opinion dissemination, fermentation. In 2016, the high point of agro-products quality and safety negative public opinion appeared in August; active period of rumors is March to July or September to November, with the same pace of market season for agro-products. China's agro-products quality and safety public opinion paid more attention to the main agricultural provinces and major consumer provinces (cities), including Shandong, Guangdong, Hunan, Beijing and Heilongjiang provinces.

agro-products, quality and safety, internet public opinion, public opinion monitoring, public opinion analysis doi: 10.1360/N972017-00015 